\title{
POEMA PEDAGÓGICO: SOCIABILIDADES E RETÓRICA NA EDIFICAÇÃO DA PEDAGOGIA DE ANTON MAKARENKO
}

\author{
Cristiane Fernanda Xavier ${ }^{1}$ \\ Marcelo Hornos Steffens ${ }^{2}$
}

\section{RESUMO}

O objetivo deste trabalho é discutir o processo de edificação, validação e circulação da pedagogia de Anton Makarenko no contexto da Rússia pós-revolução. Por meio do exame da retórica e das sociabilidades intelectuais construídas e mobilizadas por Makarenko na produção e divulgação da sua obra Poema Pedagógico é possível verificar que o autor se esforçou para construir a ideia de uma conexão desinteressada com Máximo Gorki - figura central na promoção da sua obra - e de que a sua pedagogia fora desenvolvida à margem do oficial. Paradoxalmente, Poema Pedagógico se apresenta vinculada ao projeto revolucionário soviético na mesma medida em que buscou atender aos requisitos de uma literatura soviética nos moldes propostos pelo próprio Gorki.

Palavras-chave: história dos intelectuais, história da educação, narrativas memorialísticas, história da União Soviética.

\footnotetext{
${ }^{1}$ Universidade Federal de Alfenas (Unifal), Alfenas/MG, Brasil.

${ }^{2}$ Universidade Federal de Alfenas(Unifal), Alfenas/MG, Brasil.
} 


\section{POEMA PEDAGÓGICO: SOCIABILIDAD Y RETÓRICA EN LA EDIFICACIÓN DE LA PEDAGOGÍA DE ANTON MAKARENKO}

\section{RESUMEN}

El objetivo de este trabajo es analizar el proceso de edificación, validación y circulación de la pedagogía de Anton Makarenko en el contexto de la Rusia post-revolución. Mediante el examen de la retórica y la sociabilidad intelectual construido y movilizado por Makarenko en la producción y difusión de su Poema Pedagógico trabajar se puede ver que el autor se ha esforzado para construir la idea de una conexión desinteresado a Maxim Gorki - una figura central en la promoción de su obra - y que su pedagogía se ha desarrollado fuera de las orientaciones oficiales. Paradójicamente, Poema Pedagógico aparece vinculada al proyecto revolucionario soviético en la misma medida en que se trató de cumplir con los requisitos de la literatura soviética según lo propuesto por el propio Gorki.

Palabras clave: historia de los intelectuales, historia de la educación, memorias, historia de la Unión Soviética.

\section{POEMA PEDAGOGICO: SOCIABILITIES AND RHETORICS IN THE EDUCATION OF ANTON MAKARENKO'S PEDAGOGY}

\section{ABSTRACT proposed by Gorky himself. Soviet Union. \\ POEMA PEDAGOGICO: SOCIABILITES ET LA RHETORIQUE DANS LA CONSTRUCTION DE LA PEDAGOGIE D'ANTON MAKARENKO}

This paper aims to discuss the process of building, validating and circulating Anton Makarenko's pedagogy in the context of post-revolution Russia. Through the examination of the rhetoric and the intellectual sociabilities constructed and mobilized by Makarenko in the production and dissemination of his work Road to Life, it is possible to verify that the author endeavored to construct the idea of an uninterested connection with Maxim Gorky - central figure in the promotion of his work - and that Makarenko's pedagogy had been developed on the margins of the official. Paradoxically, Road to Life is linked to the revolutionary Soviet project to the same extent that it sought to meet the requirements of a Soviet literature in the molds

Keywords: history of intellectuals, history of education, memorial narratives, history of the

\section{RESUME}

L'objectif de ce travail est débattre le procès de construction, de validation et de diffusion de la pédagogie d'Anton Makarenko dans le contexte de la Russie post-révolutionnaire. Par l'examen 
de la rhétorique et des sociabilités intellectuelles construites et mobilisées par Makarenko dans la production et la diffusion de son œuvre Poème pédagogique, il est possible vérifier que l'auteur s'est efforcé à construire un lien désintéressé avec Máximo Gorki - personne centrale dans la promotion de son travail - et que sa pédagogie avait été développée en marge d'officiel. Paradoxalement, le poème pédagogique est lié au projet révolutionnaire soviétique dans la même mesure qu'il a cherché à répondre aux exigences d'une littérature soviétique dans les moules proposés par Gorki lui-même.

Mots-clés: histoire des intellectuels, histoire de l'éducation, récits de mémoire, histoire de l'Union soviétique. 


\section{INTRODUÇÃO}

Este trabalho analisa a obra Poema Pedagógico3, na qual se encontra relatada a experiência de Anton Semionovitch Makarenko (1888-1939) como diretor da Colônia Gorki (1920-1928) a fim de compreender a atuação do autor na edificação, validação e circulação de um modo de pensar e realizar a educação no contexto da Rússia pós-revolução, até os anos de 1930.

Ocorre que na Rússia pós-revolução a educação foi tida como elemento fundamental na construção de uma nova sociedade sem classes. Logo nos primeiros dias da tomada de poder pelos bolcheviques uma série de decretos relativos à organização da educação foram baixados. Em outubro de 1917, após a instituição do NarKomPros ${ }^{4}$, foi criada a Comissão Estatal para a Educação Nacional que, dentre outras responsabilidades, deveria elaborar projetos de lei para a reorganização do ensino e da educação nacional. Daí em diante, tarefas como ações de combate ao analfabetismo, edição e tiragem de obras educacionais, organização de escolas experimentais, sublinhavam o papel da instrução pública como política estratégica no processo revolucionário.

Haja vista o destaque da instrução no contexto acima referido, o texto a seguir examina a retórica e as sociabilidades intelectuais construídas e mobilizadas pelo educador e intelectual Anton Makarenko na produção e divulgação da sua pedagogia. Nessa perspectiva, também lança luz sobre o lugar da educação no conjunto das transformações ocorridas na sociedade russa naquele ambiente de ruptura e transição do regime czarista para o desenvolvimento de uma ordem socialista de sociedade.

\footnotetext{
3 Poema Pedagógico foi originalmente publicado em três partes nos anos de 1933, 1934 e 1935. No Brasil, a primeira edição da obra foi publicada pela Editora Brasiliense em três volumes, entre os anos de 1985/1986. Em 2005, a Editora 34 lançou a primeira edição do livro em um único volume. Neste trabalho a análise se refere à edição de 2005.

4 O NarKomPros ou Comissariado do Povo de Educação - órgão responsável pela administração da educação pública - foi criado em 1917 com a tarefa de reconstruir o sistema educacional russo em substituição ao antigo órgão dedicado às questões educacionais da época czarista e presido por A. V. Lunacharsky até o ano de 1929 (FREITAS; CALDART, 2017).
} 


\section{ANTECEDENTES: A CONSTITUIÇÃO DO HOMEM NOVO E A EMERGÊNCIA DA EDUCAÇÃO NA CONSTRUÇÃO DE UMA NOVA SOCIEDADE SEM CLASSES}

O contexto que precedeu a atuação profissional e intelectual de Makarenko aponta que a Rússia pré-revolucionária era um império cheio de contrastes. Do lado da Rússia moderna encontravam-se grandes cidades como São Petersburgo e Moscou, que nada deviam às grandes metrópoles europeias com seus teatros, tabacarias e cafés. Numa espécie de região de transição vivia uma parcela da população que ocupava pequenas cidades onde se misturavam atividades tipicamente urbanas a atividades rurais. Do lado da Rússia arcaica estava uma grande massa camponesa que vivia da terra, numa forma particular de trabalho servil (MARABINI, 1989).

A tensão entre esses três mundos na Rússia levou, desde o século XIX, a algumas tentativas de modernização das relações de propriedade e trabalho no campo. Alexandre II, um dos czares reformistas, por exemplo, tentou instituir uma reforma agrária no império, em 1861. Em princípio, essa tentativa teve sucesso, no entanto, como as terras disponíveis para a reforma agrária deveriam ser compradas, os camponeses russos se endividaram junto a bancos e usurários para tornarem-se proprietários de uma parcela de terra. Quando esses empréstimos começaram a vencer, a terra teve que ser vendida. Como consequência, os kulaks obtiveram mais terras e se tornaram ainda mais ricos.

Do ponto de vista da organização política, o regime czarista era autocrático e hereditário. A justiça estava inteiramente submetida aos interesses da diminuta aristocracia que dava base ao governo dos Romanov. Uma assembleia (Duma) assinalava a existência de algum poder legislativo, que para funcionar, contudo, dependia da convocação do próprio czar. A repressão também era outra característica do sistema russo, que se assentava sobre a Okhrana, polícia secreta responsável pela espionagem e ações internas na Rússia. Além disso, o regime tinha apoio incondicional da Igreja Ortodoxa, que 
funcionava como uma espécie de porta-voz do governo nos mais remotos lugarejos do império.

Quanto à política externa, a posição russa não deixava de ser surpreendente. Nicolau II, dando continuidade à política de seus antecessores, almejava tornar a Rússia um grande império, que influenciaria a política europeia e asiática. Entretanto, as pretensões dos Romanov frustraram-se tanto com a Guerra da Criméia (1853-56), quanto com a guerra contra o Japão (190405).

Contudo, apesar do forte sistema repressivo, existia oposição ao czar e ao regime czarista. Ações terroristas de inspiração anarquista ocorriam com alguma frequência. Grupos reformistas e revolucionários, de inspiração marxista, também agiam de forma clandestina na Rússia.

Especialmente a partir da eclosão da Revolução de 1905, marcada pelo chamado Domingo Sangrento, quando foram fuziladas pela guarda do czar centenas de pessoas que marchavam pedindo reformas sociais, Nicolau II sentiu-se impelido a realizar algumas tentativas de fortalecimento do regime. Inicialmente, permitiu a rearticulação da Duma, que serviria como base de ação para políticos reformistas. Paralelamente a essa rearticulação, o clima político esquentou nas grandes cidades, onde a concentração e a organização operária aumentavam, particularmente com a criação de inúmeros sovietes (Conselhos) que instituiriam formas diretas de participação política. Além do mais, o Partido Operário Social Democrata Russo (POSDR), conhecido como bolchevique, comandado por Lenin e de base marxista, crescia significativamente entre o operariado russo (REIS FILHO, 2005).

Como dito, Nicolau II se viu obrigado a realizar reformas que não o agradavam, uma vez que liberalizavam o regime autocrático. No entanto, com a eclosão da Grande Guerra (1914-1918) ele viu a oportunidade de arrefecer os ânimos e usar ao máximo o nacionalismo russo que andava desgastado com os fracassos anteriores na Criméia e no Japão. Assim, a Grande Guerra deu alguma margem de manobra para o cambaleante regime czarista, dividindo o império - 
inclusive a oposição e o próprio movimento revolucionário - entre aqueles que defendiam a entrada da Rússia na guerra e os contrários a ela. Como no restante da Europa, venceu a corrente de opinião que apoiava o conflito uma vez que a expectativa dominante era a de que ele se desenrolasse rápida e favoravelmente.

No entanto, a Guerra prolongou-se além das previsões. O regime czarista, que era também débil economicamente, sofreu os impactos disso. $\mathrm{O}$ exército russo, comandado por oficiais tradicionais ligados à aristocracia czarista, teve imensas perdas e num determinado momento foi deixado à própria sorte, sem mantimentos, armas e munições o que produziu uma grande onda de deserções e abandono do front de guerra. Além disso, o boato de que as terras na Rússia estavam sendo distribuídas aos camponeses fez com que esse movimento de deserção tomasse proporções ainda maiores.

A situação de crise econômica e política - passeatas contra o regime, insurgência das tropas contra o governo, inclusive dos cossacos, membros da cavalaria da guarda especial czarista - agravada pela permanência da Rússia na guerra forçou a renúncia de Nicolau II, ocorrida em 2 de março de 19175. Com a renúncia, um governo provisório foi formado a partir da Duma; comandada por Kerenski, reformista, e com a participação de membros do soviete de Petrogrado.

Mas a direção que o governo provisório tomou acabou por isolá-lo cada vez mais de outros grupos revolucionários. Kerenski defendia a permanência da Rússia na guerra - razão fundamental para a abdicação de Nicolau II - assim como, uma monarquia constitucional com a preservação do czar. Seu governo atacava os socialistas e anarquistas tentando evitar qualquer iniciativa que partisse desses grupos (REIS FILHO, 2015).

No entanto, os revolucionários aproveitaram-se da inoperância do governo provisório para se articular e avançar na direção de sua derrubada e na

\footnotetext{
5 Conforme o calendário juliano, então vigente na Rússia. De acordo com o calendário ocidental, 15 de março de 1917. Usaremos como referência o calendário juliano, colocando entre parênteses a data ocidental. A indicação de apenas uma data corresponderá à unificação dos calendários.
} 
formação de um novo governo. Assim, em 25 de outubro (07/11) de 1917 o Palácio de Inverno - sede do governo provisório - foi ocupado pelas tropas de oposição, destituindo-se o governo de Kerenski e iniciando a formação de um novo governo.

Contudo, a vitória inicial da oposição e dos bolcheviques contra Kerenski e o czarismo marcou um novo momento nesse processo, e talvez o momento mais crítico da revolução soviética. Teve início a guerra civil, capitaneada pelos russos brancos - antigos membros do regime czarista - por partidários de Kerenski e mais tarde pelos exércitos estrangeiros enviados pelos governos da França, Inglaterra e Alemanha, dentre outros, até então inimigos na Grande Guerra, ciosos de protegerem os investimentos de seus súditos na Rússia e, talvez, de abocanharem algum território naquele imenso império que ameaçava desintegrar-se.

A guerra civil durou quatro anos (1918-1921) e teve um efeito devastador sobre o novo país que tentava se organizar. A antiga Rússia, transformada em União das Repúblicas Socialistas Soviéticas (URSS), em 30 de dezembro de 1922, tinha que se reconstruir. Sua população havia sido dizimada - particularmente o operariado urbano, a parcela mais engajada na luta política -, sua economia estava acabada com índices de produção anteriores aos da Grande Guerra. Enfim, o país estava destruído. O Comunismo de Guerra de Trotski que funcionara durante a guerra civil, agora enfrentava boicote dos camponeses, o que tornava ainda mais urgente a adoção de medidas que retomassem a ligação entre a produção do campo e das cidades e que garantissem a sobrevivência do novo regime.

Lenin via como solução provisória o retorno temporário às formas capitalistas ou a um capitalismo controlado pelo Estado. Propôs assim a Nova Política Econômica (NEP). Ela, inegavelmente, funcionou. Vários índices de produção atingiram números semelhantes aos anteriores à Grande Guerra. No entanto, como efeito colateral, fortaleceram-se determinados grupos sociais que se distanciavam do socialismo, em especial os kulaks. 
Com a morte prematura de Lenin, ocorrida em janeiro de 1924, Josef Stalin assumiu, não sem contestações, a função de secretário geral do Partido Comunista da Rússia. Ele se deparou com um dos grandes dilemas da revolução: redirecioná-la para o socialismo ou correr os riscos de uma volta ao capitalismo, com a manutenção da NEP. Stalin e os membros do Partido escolheram a primeira opção. Dessa forma os traços do capitalismo deviam ser eliminados.

Iniciou-se o processo de acumulação primitiva socialista, onde as execuções e a violência faziam parte das ações corriqueiras. Junto com esse processo de progressiva centralização política pelo e para o alto, em 1928 instituíram-se na economia os Planos Quinquenais que estabeleciam metas que deveriam ser alcançadas no seu período de execução além de uma intensa propaganda estatal pela qual buscavam motivar os trabalhadores para que os índices planejados fossem atingidos. Ou seja, no horizonte desses propósitos estava a organização e desenvolvimento de uma ordem socialista em contraponto e alternativa ao ordenamento capitalista mundial e ao regime czarista sob o qual se assentava a estrutura política russa (VIZENTINI et al., 1989).

Em meio a esse complexo cenário estava em pauta a questão da necessidade de formar um homem novo para uma nova sociedade. No plano educacional essa demanda foi assumida pelo NarKomPros e, para tanto, uma das suas ações foi a criação de escolas experimentais, chamadas de EscolasComunas. Estas instituições eram tidas como "local de agregação de grandes e experientes educadores que se dedicavam a criar novas formas e conteúdos escolares sob o socialismo com a finalidade de transferir tais conhecimentos para as escolas regulares, de massa" (FREITAS, 2013, p. 13). Nesse contexto foi que, em 1920, Makarenko recebeu a incumbência de dirigir uma colônia pedagógica experimental, posteriormente chamada de Colônia Gorki; trabalho que desenvolveu até 1928 e narrou no livro Poema Pedagógico. 


\section{ANTON SEMIONOVITCH MAKARENKO: EDUCADOR E INTELECTUAL}

Makarenko nasceu na Ucrânia, em março de 1888. Iniciou a sua carreira profissional aos 16 anos como professor de língua russa, na Escola Primária Ferroviária de Kriukov. Desde então, especialmente sob a influência dos escritos de Máximo Gorki (1868-1936), foi desenvolvendo a compreensão do fenômeno pedagógico como prática política. Diplomou-se em Pedagogia em 1917, mas em 1911 já atuava na condição de inspetor da instrução pública de Dolinskaia. Casou-se em 1927 com a pedagoga Galina Stakhievna Salko, dirigente do Comissariado do Povo para a Instrução Pública da Ucrânia e "sua grande incentivadora intelectual”. Nesse mesmo ano propôs a unificação das 18 colônias de trabalho então existentes na região de Kharkov, para funcionar com um complexo pedagógico único. Esta proposta, "aceita pelo Comissariado do Povo para a Instrução Pública da Ucrânia, serviu de base para a criação da Direção Geral das Colônias Infantis, sob a responsabilidade de Galina Salko e que tinha o próprio Makarenko como diretor pedagógico". Ainda em 1927, Makarenko e Galina produziram, em parceria, O livro dos pais (FILONOV, 2010, p. 132).

Ainda segundo G. N. Filonov (2010), em 1928, Makarenko deixou a Colônia de Gorki para assumir a direção da Comuna Dzerjinski. Em 1934, ingressou como membro militante na União de Escritores Soviéticos ${ }^{6}$. A partir de 1937 passou a se dedicar integralmente ao ofício literário e à realização de palestras, conferências e participação em programas de rádio. Além de livros e artigos publicados, Makarenko colaborou em jornais, escreveu roteiros literários para filmes, romance e peça teatral. Faleceu em abril de 1939, em Moscou.

\footnotetext{
${ }^{6}$ A União dos Escritores Soviéticos foi criada em 1932, pelo Comitê Central do Partido, após a decisão de dissolver todas as associações literárias existentes. Segundo Homero Freitas de Andrade (2010), "com a criação da União, punha-se fim à briga entre os vários grupos literários que disputavam a hegemonia nas letras soviéticas. Mas não só: um único órgão reunindo todos os escritores da URSS permitia ao partido exercer mais facilmente o controle sobre a produção dos 'engenheiros da alma humana'. Do ponto de vista político, representou 'um hábil movimento para a supressão de todo não conformismo e para um controle totalitário da vida cultural e espiritual" (ANDRADE, 2010, p. 159).
} 
As atividades e ações realizadas por Makarenko permitem compreendêlo como educador e como intelectual. Segundo Michel Winock (2000), pela expressão intelectual é possível designar formas distintas de engajamento dos homens de pensamento. Conforme o autor, o intelectual que faz uso da sua notoriedade para criticar a sociedade e os poderes estabelecidos e que em nome da humanidade assume uma função moral na condição de oficiante da justiça abstrata se difere daquele intelectual que, por seu prestígio, mergulha numa rede de equipes e influências tomando partido nos problemas da vida social com base em suas filiações ideológicas.

Além das diferenças que caracterizam os modos de engajamento do intelectual, chama a atenção nesse debate o lugar dos interesses pessoais no rol das motivações que mobilizam os intelectuais para a atuação. Sobre isso, Winock aponta para trabalhos que foram desenvolvidos especialmente a partir dos anos de 1980 e que também incluíram a discussão sobre as estratégias individuais utilizadas pelos intelectuais na defesa de seus próprios interesses. $\mathrm{Na}$ esteira do desencanto e desconfiança em relação aos limites do estilo sacerdotal de engajamento intelectual, e, portanto, no âmbito do abalo da autoridade intelectual7, Winock destaca que estes trabalhos incluíram a questão das motivações pessoais ${ }^{8}$ nos feitos e atitudes dos intelectuais com vistas à

7 É comum encontramos na literatura especializada o caso Dreyfus como referência na caracterização de uma autoridade moral conferida aos intelectuais. Com base nesse caso, em 1927, Julien Benda publicou A traição dos intelectuais (Trahison des clercs) na qual condenou os intelectuais, "que entregues às paixões políticas, perdiam o ponto de vista universal e comprometiam sua autoridade em causas particulares" [...]. Desde então, a obra de Benda é tida como marco na composição dos dois tipos clássicos de intelectual e ao mesmo tempo na compreensão da participação de interesses partidários e ideológicos nas suas atividades. Especialmente a partir dos anos de 1980, haja vista o abalo na reputação política de Michel Foucault em função do seu apoio ao aiatolá Komeini que retornara do exílio em 1978 para fundar um regime islamita no Irã bem como a tese de Bourdieu sobre o fascínio que a televisão exercia sobre aqueles que dela falavam tão mal, dentre outros exemplos, houve um movimento de suspeição em relação aos intelectuais que desembocou numa releitura das ações dos grandes e pequenos escritores e intelectuais.. Todo esse processo de dessacralização do intelectual foi, portanto, fundamental para os estudos orientados para a compreensão das estratégias individuais dos intelectuais na realização dos seus projetos e na difusão das suas ideias e defesas (WINOCK, 2000, p. 791).

${ }^{8}$ Sobre a incapacidade dos intelectuais dominarem suas próprias paixões, Mark Lilla (2017) aponta que ao lado do comunismo e do fascismo, a Europa também deu à luz um novo tipo de intelectual. O intelectual desse tipo, de acordo com o autor, "entra na vida política não como 
aquisição de bens materiais e simbólicos.

Também é possível associar Makarenko à ideia do intelectual como ator do político, ao modo proposto por Jean-François Sirinelli (2003). Por meio da noção de redes de sociabilidades, Sirinelli chama a atenção para a importância do estudo da formação dos grupos de apoio de um intelectual para a compreensão da atmosfera intelectual de uma época. Nesse processo de formação, a dinâmica de funcionamento de uma intelligentsia é operada, de forma interpenetrada, pelo afetivo e pelo ideológico. Isto é, para Sirinelli, a razão nem sempre prevalece na elaboração de ideias, na divulgação de propostas ou na adesão dos intelectuais a determinadas causas.

Tendo em conta as referências assinaladas, Makarenko foi um intelectual pragmático em detrimento da ideia do intelectual como sendo a personificação do saber desinteressado, atemporal e distante da realidade mundana. Compreendido como tal, coube identificar as sociabilidades intelectuais construídas e mobilizadas em torno da publicação de Poema Pedagógico, a fim de observar os grupos de apoio que autorizaram e legitimaram o modo de Makarenko pensar e realizar a educação ao ponto de torná-lo, segundo Franco Cambi (1999), uma espécie de pedagogo oficial da Rússia soviética ao longo de décadas.

Ocorre que, a esfera artístico-literária ocupou um lugar central na cultura russa pós-revolucionária. Da livre ligação da cultura com a sociedade de outrora, a cultura soviética tornou-se subordinada à política do poder estatal de um único partido. Naquele contexto as linguagens artística e literária foram

governante, mas como professor, orador, poeta" devido que "existe alguma ligação na mente humana entre o anseio pela verdade e o desejo de contribuir para o "correto ordenamento das cidades e dos lares". Entretanto, é exatamente por reconhecer essa necessidade como "necessidade" que um impulso pode tornar-se uma paixão imprudente. Daí considerar que as "doutrinas do comunismo, fascismo, marxismo em todas as suas permutações barrocas, do nacionalismo, do terceiro-mundismo - muitas inspiradas pelo ódio à tirania - foram todas capazes de inspirar tiranos cheios de ódio e cegar intelectuais para seus crimes”. E acrescenta: "É possível conceber essas tendências como parte de uma grande narrativa histórica à qual possa ser atribuída alguma força externa, movendo tantos os acontecimentos quanto suas interpretações. Mas, por mais que reflitamos sobre essas forças, ainda estamos longe de apreender as lutas íntimas que os intelectuais europeus tinham com elas e os muitos artifícios que empregaram para preservar suas ilusões" (LILLA, 2017, p. 183). 
entendidas como dotadas de uma capacidade comunicativa mais apta ao contato com estratos mais amplos da sociedade, bem como canais de verificação e de influência no combate e destruição da religião.

Como dito, em decorrência dos propósitos da revolução socialista, a Rússia se envolveu no compromisso de criar um homem novo para uma nova sociedade. Oficialmente, a partir de 1934, este compromisso foi expresso pelo movimento chamado de realismo socialista, estilo artístico aprovado pelo regime comunista por ocasião do $1^{\mathrm{o}}$ Congresso da União dos Escritores Soviéticos. Sob as prerrogativas deste movimento as artes foram convocadas a assumir a tarefa de "fornecer uma visão positiva e confiante de um povo e de uma revolução, conduzidos por um partido monolítico, coeso e organizado", face às necessidades sociais e políticas do momento. Nesse sentido, o realismo socialista marcou o campo das artes pela tendência a um distanciamento da provocação e do debate para tornar-se o "enaltecimento da Revolução e do povo russo na sua luta para criar uma nova sociedade" ou ainda, para tornar-se "uma gramática revolucionária para servir a uma revolução" (LOPEZ, 1989, p. 155, 159).

Com base nos objetivos de controlar a produção artística e direcioná-la para a propaganda aliadas à crença no poder da literatura, as autoridades se envolveram na busca por cânones. Para tanto, tornaram a obra A mãe, de Gorki, o modelo supremo do realismo socialista a fim de "mostrar a luta do proletariado rumo ao socialismo e o papel das lideranças revolucionárias" (FIGUEIREDO, s/d, p. 83).

Enquanto isso, conforme afirma Filonov (2010), Makarenko mantinha contato com Gorki desde 1914. Envia-lhe os manuscritos que redigia para que fossem avaliados pelo escritor. Principal expoente da arte proletária, da ideologia da cultura proletária e um dos teóricos do realismo socialista, Gorki considerava que a característica particular da "grande literatura russa e que lhe dá a originalidade e a força que exercem influência cada vez mais notável e profunda sobre a literatura do mundo inteiro" era a sua capacidade de "conjugar 
realismo e romantismo". Isso significava articular uma "representação verídica, nua e crua das pessoas e de suas condições de vida" com o fortalecimento da "vontade que o homem tem de viver, despertando nele uma revolta contra a realidade, contra qualquer opressão" (GORKI, 2006, p. 164).

Foi, aliás, essa relação que possibilitou a publicação de Poema Pedagógico em periódico dirigido por Gorki. O contato entre os escritores, o trabalho de Makarenko, além do prestígio e influência de Gorki também rendeu a produção do filme O caminho da vida, de 1931. Obra na qual o cineasta Nikolai Ekk, narrou o trabalho de Makarenko na Colônia de Gorki. "Em 1932 foi escolhido, pelo público, como o melhor filme do Festival de Veneza. Com o sucesso alcançado nessa cidade italiana, 'O caminho da vida' percorreu praticamente o mundo todo" (FILONOV, 2010, p. 132).

Se do ponto de vista literário, há razões para reconhecer Poema Pedagógico como um exemplar do realismo socialista, do ponto de vista político talvez a obra seja mais do que uma literatura de partido. Pode ser que Poema Pedagógico também expresse a existência de lugares de enunciação e modelos de pedagogia comunista em disputa. E há pelo menos dois aspectos que apoiam esta possibilidade: o fato de Makarenko insistir que o seu trabalho fora desenvolvido sob duras críticas do Comissariado do Povo para a Instrução Pública (aspecto que será explorado mais adiante) e o papel central desempenhado por Gorki na divulgação do trabalho de Makarenko.

É que segundo Jutta Scherrer (1984), Gorki compunha com outros intelectuais a chamada ala esquerda da fração soviética. Essa fração de expressivo peso político, encabeçada por Bogdanov, incluía: Lunatcharski, Krasin, Alexinski, Bazárov, além do próprio Gorki e outros estreitamente a eles vinculados. Juntos, representavam "não somente o maior potencial intelectual dos bolcheviques como também defendiam uma concepção não ortodoxa do marxismo e a tese de que o conhecimento se baseia unicamente na experiência laborativa organizada da sociedade" (SCHERRER, 1984, p. 193).

Popular entre os operários, Bogdanov já havia anunciado seu 
rompimento com Lenin, em 1909, por considerar que a tática revolucionária do bolchevismo na época intra-revolucionária consistiria em preparar o proletariado russo para dirigir ele mesmo seu próprio movimento, do ponto de vista organizativo, tático e ideológico, e criar assim as bases para a renovação do Partido. No campo da cultura e da literatura, Bogdanov foi responsável pela criação do Proletkult. Segundo Homero Freitas de Andrade (2010), o projeto do Proletkult consistia na implementação de uma literatura e de uma arte proletárias. Agrupava escritores e artistas, promovia debates, espetáculos bem como editava jornais e revistas.

Além disso, o programa do Proletkult "postulava a autonomia da revolução cultural com relação ao poder político do governo e do Partido Comunista e concebia essa revolução como construção imediata de uma cultura puramente proletária”. E nesse sentido, o programa do Proletkult não era aceito por Lenin ${ }^{9}$ (STRADA, 1984, p. 128).

Bogdanov também foi responsável pela formulação de uma particular corrente teórica, conhecida como filosofia do coletivismo, cujo postulado centrava-se na interdependência entre técnica e ideologia. Na sua proposição, a cultura coletivista caracterizava-se pela ideia e pelo ideal da coletividade laborativa na qual o coletivo operário, além da função executiva, assumiria a função deliberativa e no qual 'a harmonia e a força do coletivo tornam-se a essência do progresso humano’ (SCHERRER, 1984, p. 205-206).

Longe de pretender esgotar o pensamento de Bogdanov, interessa destacar que figuras de primeiro plano da vida cultural soviética como Gorki e Lunatcharski colaboram com Bogdanov desde os tempos da sua cisão com Lenin, compartilhando das suas ideias e dando vida a sua corrente teórica por meio da escola de partido de Capri. Aliás, a literatura especializada afirma que

\footnotetext{
9 N. K. Krupskaya (1869-1939) - esposa de Lenin e importante liderança no grupo que formulou as concepções que orientariam a política educacional do Comissariado do Povo para a Educação na Rússia soviética - também compartilhava com Lenin da discordância em relação ao programa do Proletkult. A oposição de Krupskaya ao programa do Proletkult pode ser lida na obra N. K. Krupskaya: A construção da pedagogia socialista - escritos selecionados (FREITAS; CALDART, 2017).
} 
na manifestação solene de Gorki em apoio ao realismo socialista no informe de abertura que proferiu no I Congresso dos Escritores Soviéticos, "um eco das ideias de Bogdanov chegou ao realismo socialista ao reafirmar a religião coletivista do trabalho e desvalorização de toda a cultura burguesa" (STRADA, 1984, p. 194).

Nesse sentido, Gorki era representante de um movimento que defendia a criação de uma cultura proletária em oposição à ideia de que somente a vanguarda que absorveu a energia revolucionária da classe (nesse caso, o Partido) seria capaz de exercer a ditadura do proletariado. Dado o contato de Gorki com Makarenko, é muito difícil imaginar que as ideias, posições e prestígio do primeiro não tenham exercido influências sobre a atuação do segundo. Afinal, no limite, Gorki não só autorizou e legitimou uma obra literária como colocou em circulação uma proposta político-pedagógica específica. Da mesma maneira, parece improvável que Makarenko ignorasse a autoridade de Gorki como escritor, a sua proximidade com Lenin e Stálin e a sua influência junto ao alto escalão do Partido.

\section{“NÓS SOMOS OS GORKIS": ASPECTOS ORGANIZATIVOS E FORMAÇÃO IDENTITÁRIA DA COLÔNIA}

Sem desconsiderar a problematização possível em torno da liberdade artística produzida pelo realismo socialista como pano de fundo à época da publicação de Poema Pedagógico, tal fonte foi entendida como expressão de um processo histórico que conferiu à memória uma possibilidade de alargamento através do registro escrito. $\mathrm{O}$ uso de narrativas memorialísticas de docentes como fonte de pesquisa em educação é expediente conhecido na área. Tais fontes tem permitido estudar a atuação profissional de professores/as, apreender a cultura escolar de uma época bem como compreender contextos, as finalidades e motivações que animam educadores a colocarem as suas 
experiências no papel. Da mesma maneira, práticas de produção de si, expressas em diários ou autobiografias, tem possibilitado o exame da história do individuo e dos seus grupos de pertencimento, suas sociabilidades e interdependências no tempo e no espaço ou ainda, a compreensão da produção ou do engajamento de educadores na defesa de determinadas causas.

Sobre o valor da memória na evolução das sociedades Jacques Le Goff (2003) aponta que ela (a memória) é um elemento essencial da identidade, individual ou coletiva, cuja busca é uma das atividades fundamentais dos indivíduos e das sociedades. A busca pela construção de identidades através da memória ocorre no interior de um processo de conquista e relações de poder nas quais estão envolvidos conteúdos sociais, culturais, emocionais, mitológicos, orgânicos e tecnológicos. Daí que a narrativa da memória é entendida como uma atividade que revela e esquece, que sublinha e relativiza, altera, adequa, revisa, cria e se apresenta por meio de documentos, monumentos, filmes, fotografias, biografias, dentre outros.

Sendo processo de conquista e relações de poder informados por diferentes conteúdos, Le Goff argumenta que a investigação baseada nas narrativas expressas pela memória contém uma dimensão monumental. Isso porque narrativas desse tipo apresentam um caráter intencional prescrito por um conjunto de interesses que terminam por evidenciar alguns elementos da realidade vivida e por silenciar outros, no esforço de construir e de impor uma determinada imagem da sociedade e dos grupos que a constituem para ser perpetuada.

Nesse sentido, o documento deve ser desmontado para que seja possível evidenciar suas condições de produção. Por sua vez, desvelar a dimensão monumental do documento requer reconhecer as condições de produção como expressão das relações de poder e como resultado de escolhas, seleções e formas intencionais (ou não) de deixar registrados os conteúdos da realidade. Afinal, "a sinceridade [...] não pode ser confundida com a verdade dos fatos e a verdade, por sua vez, não existe em nenhum tipo de documento" (GOMES, 2004, p. 17). 
Uma das maneiras possíveis de desmontar o monumento contido no documento é o estudo da retórica do remetente. A retórica funciona como um recurso de convencimento no qual o argumento é o seu instrumento. Por sua natureza, conforme José Murilo de Carvalho (2000), a retórica está orientada pela persuasão e por isso lança mão de argumentos de natureza não-lógica como figuras de linguagem, redundâncias e repetições. Além dos argumentos e dos interlocutores, a pessoa do orador também concorre como elemento da retórica posto que a sua autoridade, seja pela competência, prestígio ou honestidade, atua como ferramenta de convicção e de convencimento.

À luz dessa perspectiva, a Colônia Gorki foi uma instituição experimental fundada para educar crianças e jovens cujas trajetórias continham traços do abandono, do analfabetismo, da exclusão e da delinquência; frutos da Rússia czarista e da Guerra Civil. Imbuído da causa de educar o homem novo, contando com parcos recursos físicos, financeiros, de pessoal, enfim com escassez de toda ordem, Makarenko assumiu essa tarefa. Nesse contexto, o processo de formação e consolidação do homem novo foi operado por Makarenko no sentido de educar para a resistência. Para tanto, os colonistas deveriam aprender a não temer perigos e muito menos o sofrimento físico e a orientar suas ações para o trabalho, a sobriedade, o estudo e a solidariedade.

Eu me permiti externar a minha profunda convicção de que, enquanto não estiverem criados o coletivo e os órgãos do coletivo, enquanto não existirem tradições e não forem criados hábitos elementares de trabalho e de vida, o educador tem o direito, e não deve renunciar a ele, de usar a força e obrigar. Afirmei também que não era possível basear toda a instrução sobre o interesse, que a educação do senso de responsabilidade e do dever muitas vezes entra em conflito com o interesse da criança, em especial da forma como esta o entende. Eu exigia a educação de um ser humano resistente e forte, capaz de executar também trabalhos desagradáveis e trabalhos tediosos, se eles são requeridos pelos interesses do coletivo (MAKARENKO, 2005, p. 132).

Tal processo envolveu: organização do espaço físico da Colônia (limpeza 
e reforma), coleta de bens materiais e de mobiliário, arrecadação de suprimentos; disciplinarização dos colonistas (castigos, ameaças, surras, confinamentos, repreendas, controle dos vícios), provimento auto-sustentável da instituição (prestação de serviços- carpintaria- trabalho agrícola, comércio de porcos e visitação paga às pocilgas), adoção dos princípios da instrução militar (atividades físicas, organização do trabalho nas oficinas por meio dos destacamentos permanentes e mistos, conselho soviete de comandantes, eleições, reuniões e assembleias, regime de plantões) ${ }^{10}$.

As estações do ano orientavam o calendário de atividades da Colônia. Assim, os colonistas trabalhavam no verão (mas também no outono e primavera) e a escola funcionava no inverno. E embora Makarenko praticamente não aborde o trabalho educacional desenvolvido na escola da Colônia é possível identificar que esta se orientava para a preparação para exame de admissão dos colonistas nas faculdades operárias (Rabfaks $\left.{ }^{11}\right)$.

Em meio a essa organização, dentre as práticas educativas rotineiras da Colônia Gorki consta as leituras comunais, atividade caracterizada pelo estudo dos clássicos. Segundo Makarenko, a leitura das obras era feita em voz alta por um dos educadores seguida pela discussão coletiva. No universo das artes, investiram na pintura e especialmente no teatro. E no campo da cultura política havia ainda o funcionamento de uma célula da União da Juventude Comunista na Colônia (Komsomoli2).

\footnotetext{
${ }^{10}$ Em relação à adoção dos princípios e práticas da instrução militar no desenvolvimento do trabalho na Colônia Gorki, vale registrar que, segundo Mario Manacorda (2013), no Oitocentos a educação física renasce no mundo educacional moderno por meio do entendimento desta como parte essencial da formação do homem. O autor afirma ainda que o tema também é encontrado "na proposta de Marx que, em 1866, incluía no seu programa para a formação do homem global ou unilateral, além da instrução intelectual e tecnológica, a educação física, 'tal como é ministrada nas escolas de ginástica e nos exercícios militares" (MANACORDA, 2013, p. 349).

${ }^{11}$ As "Rabfaks foram instituídas em 1919 e ofereciam curso preparatório de três a quatro anos para ingresso na universidade a jovens trabalhadores e camponeses" (MAKARENKO, 2005, p. 78).

${ }_{12} \mathrm{O}$ "Komsomol era um braço do Partido Comunista da União Soviética, integrada por jovens de 14 a 28 anos de idade". Foi criada com o objetivo de arranjar as crianças em destacamentos e ensinar aos jovens as regras de comportamento da moralidade comunista (MAKARENKO,
} 
Makarenko foi esmero na constituição da identidade dos colonistas. Nesta operação a figura de Gorki ocupou posição privilegiada. Organizavam tertúlias literárias e "as obras de Gorki empolgavam a todos" de tal modo que "a vida de Maxim Gorki tornou-se como que parte da nossa vida”. E assim “começamos a nos denominar 'Colônia Gorki' sem qualquer disposição ou confirmação oficial. Na cidade, foram acostumando aos poucos a esse nome [...] e não protestaram contra nossos novos selos e carimbos com o nome do escritor" (MAKARENKO, 2005, p. 87).

Também escreviam para Gorki e em algumas cerimônias ou ocasiões especiais Makarenko lia cartas enviadas por ele aos colonistas incentivando-os a seguir nos estudos e no trabalho, bem como, reforçando os laços de identidade que os uniam: a pobreza e o abandono.

[...] No palco modestamente arrumado colocamos o retrato de Alexei Maximovitch. Eu falei aos jovens sobre a vida e obra de Gorki, fiz um relato minucioso. Alguns dos rapazes mais velhos leram trechos da "Infância". Os novos colonistas me ouviam, com olhos muito abertos: eles nunca imaginaram que no mundo fosse possível uma vida como aquela. Não me fizeram perguntas nem ficaram emocionados até o momento em que Lápot trouxe uma pasta com as cartas de Gorki (MAKARENKO, 2005, p. 570).

Outro interessante princípio e expediente adotado por Makarenko no processo de disciplinarização e formação de uma identidade Gorki era o de não fazer referências ao passado dos colonistas. Ou seja, na sua experiência educativa o passado era interditado. Como condição à emergência do "homem novo" a história pregressa dos colonistas era algo a ser esquecido e superado.

Além disso, Makarenko lançou mão de artefatos simbólicos e ritualísticos, sobretudo após a adoção de princípios da instrução militar na rotina diária da Colônia. Nesse sentido, operaram como fatores de identidade colonista e de coesão grupal: a organização de uma fanfarra (posteriormente 
uma orquestra), realização de paradas/desfiles/marchas, hasteamento da bandeira da Colônia (estandarte Gorki) prática de prestar continência, distribuição de condecorações e realização de discursos bem como a realização de comemorações festivas (aniversários de fundação da Colônia, transferência da sede da Colônia, casamento).

Ao longo das mais de 600 páginas, o autor narrou a sua experiência na forma de contos e utilizou o diálogo como recurso comunicativo por excelência para descrever as mais diversas situações ocorridas ao longo daqueles oito anos de trabalho na Colônia. Frequentemente as experiências contadas sugerem uma lição/ensinamento. Assim, ao incluir temas como embriaguez, antissemitismo, suicídio, aborto, preguiça, religião, jogos de cartas, Makarenko expôs alguns dos problemas que teve que enfrentar como diretor da Colônia de Gorki na disciplinarização dos colonistas, mas, sobretudo, destacou alguns dos problemas tidos como nocivos à formação do homem novo e, portanto, inimigos da revolução. Tais características tornam a obra de fácil leitura e entendimento o que pode corresponder ao estilo narrativo do autor bem como a uma estratégia de popularização dos preceitos da educação socialista visto que aquilo que Makarenko selecionou como digno de ser registrado coincide com a moral socialista e a gramática revolucionária.

Traço marcante da narrativa de Makarenko é o de descrever detidamente vários dos colonistas (tanto em relação aos aspectos físicos quanto aos traços de personalidade de cada um deles). Ao fazer uso dessa estratégia o autor se coloca no lugar de alguém autorizado a narrar a experiência da Colônia de Gorki. Com isso, ao mesmo tempo em que procura conferir veracidade à sua narrativa (eu estava lá!), Makarenko sugere que o conhecimento detalhado dos educandos é uma das condições ao trabalho de diretor de uma instituição educativa socialista.

Segundo Makarenko, alguns acontecimentos na Colônia (aborto, suicídio, espancamentos) levaram o Departamento de Instrução Pública a questionar os métodos adotados na educação dos colonistas. Ocorre que, em 
conformidade com a Deliberação do Comitê Executivo Central de toda a Rússia (1918), nenhum tipo de punição era permitido na escola; expediente ao qual Makarenko recorria com certa frequência. Outras práticas adotadas por Makarenko e que, segundo ele afirma, eram desaprovadas pelo Comissariado do Povo para a Instrução Pública foram: a instituição de um salário para os educandos e de um sistema de concorrência entre os colonistas por meio de fixação de metas e divulgação comparativa dos resultados dos trabalhos dos destacamentos. Assim, várias passagens da obra apresentam o autor na condição de convocado a prestar contas acerca do seu credo pedagógico e suas práticas ou a manifestar publicamente suas posições sobre assuntos de natureza pedagógica.

Curiosamente, a despeito da sua desobediência, Filonov afirma que "em 1925 Makarenko recebeu do próprio Comissariado do Povo para a Instrução Pública o título de 'Herói Vermelho do Trabalho'; condecoração tida como uma das mais cobiçadas honrarias concedidas pelo poder soviético". Como um complemento, "também foi premiado com uma viagem a Moscou e Leningrado pelas autoridades educacionais de Poltava" (FILONOV, 2010, p. 132).

Além da ambiguidade assinalada, interessa destacar que Makarenko conferiu à sua atuação pedagógica um caráter pioneiro e heroico. Para tanto, sublinhou a grandiosidade dos desafios que teve que enfrentar para colocar a Colônia em funcionamento assim como para tratar dos problemas cotidianos. Nesse sentido, por meio de repetições, redundâncias e ironias, destacou que a sua atividade se desenvolveu em meio à pobreza, carência, sacrifício extremo, trabalho extenuante, fome, frio e todo tipo de precariedade. Sobre a sua própria atuação, o autor afirma que não havia nenhuma literatura pedagógica disponível naquela época que fosse capaz de amparar o seu trabalho, jogar luz sobre as suas dúvidas e oferecer-lhe orientação. Com isso, tanto quanto justificar as suas recaídas pedagógicas ele também reforçou a ideia de que o seu trabalho demandou uma abordagem nova e inédita.

Mas o que dizer da originalidade de Makarenko diante da 
correspondência internacional presente nas páginas de $A$ classe operária quando este destaca, dentre outros nomes e distintas experiências, o trabalho de N. N. Solowzow na escola do trabalho denominada Revolução de Outubro?

[...] O que pode um obscuro educador realizar pela escola soviética, diz-nos de maneira precisa, a actividade de N. N. Solowzow [...]. 1921, Fome. A população local não tem outra preoccupação: como preservar-se da morte pela fome. Solowzow organiza uma escola. Reune uma cinco dezenas de crianças esfomeadas e sem recursos. É posta á sua disposição uma sala absolutamente vasia. O outomno aproxima-se, e não há lenha, e não viveres. Que fazer em taes circunstancias? Nada a fazer, parece, sinão despedir as crianças e fechar a escola. Seria procedimento de professores. Solowzow, não. Escreve o correspondente: 'Todos os dias o professor percorre a aldeia, á frente de seus alumnos, e reune o material necessario. Tudo o que se encontra sem uso, ao abandono, em casa dos camponezes, tudo era transportado para a escola, concertado, utilizado. Com admiração geral, a escola organiza, em princípios de 1922, uma serie de officinas, officina de ferreiro, de marceneiro, de sapateiro, de funileiro, de pintura, confeccionando os próprios alumnos seus calçados, seus trenós, seus bancos, etc. Apezar da fome e das más condições econômicas, o professor Solowzow creou, com o material angariado, uma communidade escolar modelo, onde o ensino se liga á produção. Sem fazer barulho em torno de sua escola, modesta mas effectivamente, passa Solowzow á realização da educação pelo trabalho. Confia a direção da escola aos alumnos, que, por intermédio do conselho escolar e de varias comissões, ajudam collectivamente o professor a erigir sua pequena comunidade. Por que aprecia tanto o governo dos Soviets a atividade do professor Solowzow? Sua atividade não tinha por base nenhuma theoria abstracta; ao fundar sua escola do trabalho não se deixou guiar por 'grandes idéas'. O valor da sua actividade está no facto de haver elle conseguido ligar ensino aos meios de producção existentes em volta de si, fazendo intelligente uso da producção para educar as crianças pelo trabalho [...] (O melhor educador na Russia dos soviets. A classe operária, o6 de junho de 1925).

\section{É possível que tamanha semelhança entre a atividade de Makarenko e}

Solowzow não somente realce as ambiguidades da retórica de Makarenko como também reforce a hipótese de que Poema Pedagógico seja a expressão da existência de lugares de enunciação e modelos de pedagogia comunista em disputa. 
Ocorre que, segundo Luiz Carlos Freitas (2017), embora a política educacional soviética da época estivesse pautada na relação entre trabalho e educação como elemento fundamental na construção de uma nova sociedade sem classes, as ênfases defendidas pelos membros do NarKomPros eram distintas. Em linhas gerais, isso significava que parte do NarKomPros defendia a oferta da escola politécnica até a idade de 17 anos sob a defesa de uma formação integral; isto é, aquela capaz de conferir centralidade ao desenvolvimento da capacidade de unir teoria e prática num todo único e na capacidade de compreender a interdependência dos fenômenos conhecidos. Ao passo que para outros segmentos do NarKomPros o foco da aprendizagem deveria estar na capacitação dos estudantes em habilidades de trabalho; isto é, defendiam a profissionalização dada as frágeis condições de desenvolvimento da grande produção.

Portanto, além das divergências em torno da cultura proletária evidenciadas pelo programa do Proletkult, havia também o problema em torno da escola do trabalho protagonizado pela disputa entre a organização da educação de base politécnica ou a educação de base profissional. Um flagrante deste debate pode ser verificado em informe sobre o ensino na Rússia. De acordo com matéria veiculada em imprensa brasileira, o jornal Pravda de 18 de outubro de 1927 indicava que:

[...] Quanto ao ensino profissional, muitos o julgam inútil, pensando que a missão do operário tende de mais a mais a limitar-se a uma simples vigilância da machina, mas, apezar disso, o Comissariado da Instrução Pública continuará a favorecel-o ( $O$ ensino na Rússia. Movimento: revista de crítica e informação, 1928, p. 20).

Haja vista a instituição de um salário e de um sistema de concorrência entre os colonistas, por meio de fixação de metas e divulgação comparativa dos resultados dos trabalhos dos destacamentos bem como uma reverência às capacidades restauradoras e pedagógicas do trabalho, pode ser que Makarenko 
representasse a parcela daqueles favoráveis à educação pela/para a profissionalização. Soma-se a isso a afirmação de Freitas (2017) de que "dentre os favoráveis à escola profissional estavam aqueles da região de Petrogrado e da Ucrânia”, onde se encontrava Makarenko (FREITAS, 2017, p. 13).

Pelo sim ou pelo não, é forçoso reconhecer que na narrativa da atuação de Makarenko há uma centralidade em relação ao postulado da função produtiva da escola bem como há poucas informações sobre as atividades escolares, propriamente ditas, desenvolvidas na Colônia Gorki. Ou seja, em Poema Pedagógico Makarenko se atém, sobremaneira, em demonstrar as faculdades regeneradoras do trabalho coletivo na disciplinarização dos colonistas e na organização e funcionamento da Colônia.

A partir de 1931, o Comitê Central do Partido Comunista assumiu a política educacional. Conforme Freitas (2013) teve lugar no NarKomPros um grande expurgo com demissões em massa. No contexto de repressão e perseguição stalinista, alguns "notórios pedagogos foram presos e fuzilados em 1937" (FREITAS, 2013, p. 17).

Àquela altura dos acontecimentos as experiências de Makarenko, primeiro na Colônia de Gorki e depois na Comuna Dzerjinski (1928-1935) haviam ganhado notoriedade. Sob a direção de Makarenko, em 1930 a Comuna Dzerjinski tornou-se a "primeira escola pública em regime de autogestão econômica em todo o mundo. Lá foram produzidas, por crianças de 13 a 15 anos, a partir de 1931, as primeiras furadeiras elétricas soviéticas, além de outros instrumentos de grande aceitação popular" [...] (FILONOV, 2010, p. 132).

As condições que determinaram a saída de Makarenko da Colônia Gorki para assumir a direção da Comuna Dzerjinski não estão claramente relatadas em Poema Pedagógico. Ele mesmo explica que a Comuna Dzerjinski era um monumento a Félix Edmúndovich Dzerjinski (primeiro presidente da Tchekán ${ }^{13}$ ) e que aconteceu naturalmente que a direção da comuna tivesse sido entregue a

13 Tcheká- abreviatura de Tchrezvitchainaia Komissia- polícia política criada em 1917 para combater a contra-revolução (MAKARENKO, 2005). 
ele. De todo modo, após a sua saída da Colônia Gorki teve início o período da chamada segunda revolução russa; fato que permite considerar a possibilidade da Colônia Gorki ter sido extinta para que a sua estrutura abrigasse uma fazenda coletiva (kolkhoze) ${ }^{14}$.

\section{CONSIDERAÇÕES FINAIS}

Para concluir, este trabalho talvez seja revelador do nosso escasso conhecimento sobre os educadores russos, as pedagogias socialistas e a relação destes com o desenvolvimento de uma ordem comunista de sociedade. Tal aspecto não somente realça a necessidade de acessar um repertório mais variado de documentos sobre a instrução pública soviética daquele período como também aponta para a complexidade em utilizar memórias como fontes de pesquisa.

Pouco sabemos, por exemplo, sobre o papel de Galina Salko, dirigente do Comissariado do Povo para a Instrução Pública da Ucrânia e esposa de Makarenko, na edificação do seu nome como pedagogo referência da educação comunista. Em Poema Pedagógico, Makarenko sequer menciona que era casado. Também fica em aberto saber se o trabalho de Makarenko na Colônia de Gorki e na Comuna Dzerjinski seriam expressões da sua filiação aos propósitos do Proletkult ou se a sua relação com Gorki estaria circunscrita ao terreno dos afetos.

Por outro lado, as ambiguidades extraídas da análise de Poema

\footnotetext{
14 A chamada segunda revolução russa, iniciada em janeiro de 1930, foi marcada, sobretudo, pela coletivização do campo com o objetivo principal de liquidar os kulaks para promover definitiva e decisivamente a construção do socialismo na União Soviética. Para Stalin e o Comitê Central do Partido Comunista, os custos humanos e naturais para a efetivação de tal processo pouco importavam. Em torno de 100 milhões de pessoas foram removidas de suas terras e obrigadas a se fixarem nas fazendas coletivas (kolkhozes). A década de 1930 também ficará marcada pelo fechamento dos debates dentro do partido e nos demais campos da sociedade soviética, desembocando no realismo socialista e no Grande Terror (FERREIRA, 2005).
} 
Pedagógico oferecem elementos interessantes para a compreensão das narrativas memorialísticas de educadores. Nesse sentido, o exame da retórica e das sociabilidades intelectuais de Makarenko permitiu analisar a sua atuação na promoção de Poema Pedagógico. Afinal, neste livro Makarenko se esforçou para fixar a ideia de que o seu trabalho fora desenvolvido à margem do oficial bem como teceu a sua narrativa dedicando-se à construção de uma conexão desinteressada com a figura de Gorki. Paradoxalmente, Poema Pedagógico é uma obra caracterizada por uma estreita vinculação ao projeto revolucionário soviético na mesma medida em que, conjugando realismo e romantismo, buscou atender aos requisitos de uma literatura à altura do país dos Soviets, tal como proposto por Gorki.

Noutras palavras, assim como o estudo das condições que autorizavam e entronaram Rui Barbosa como um grande pedagogista brasileiro permitiu a Luciano Mendes Faria Filho (2012) afirmar que "a atuação de políticos e intelectuais na edificação de seus projetos obedece muito mais a repertórios que visam ao êxito de suas ações do que a proclamados princípios doutrinários" (FARIA FILHO, 2012, p. 295), Makarenko foi incapaz de dominar suas paixões. Fechou os olhos ao autoritarismo e à brutalidade do regime soviético para satisfazer as suas aspirações políticas e seus anseios intelectuais como educador e como escritor.

\section{REFERÊNCIAS}

A CLASSE OPERÁRIA, o6 de junho de 1925.

ANDRADE, Homero Freitas de. O realismo socialista e suas (in) definições.

Literatura e sociedade, São Paulo, n. 13, 2010.

CAMBI, Franco. História da pedagogia. São Paulo: Editora Unesp, 1999.

CARVALHO, José Murilo de. História intelectual - a retórica como chave de leitura. Topoi, Rio de Janeiro, n. 1, jan./dez. 2000. 
COMITÊ EXECUTIVO CENTRAL DE TODA A RÚSSIA, COMISSARIADO DO POVO PARA A EDUCAÇÃO. Deliberação do Comitê Executivo Central de toda a Rússia, 1918. In: FREITAS, Luiz Carlos, CALDART, Roseli Salete (Org.). N. K. Krupskaya: a construção da pedagogia socialista - textos selecionados. São Paulo: Expressão Popular, 2017.

FARIA FILHO, Luciano Mendes de. A publicação das obras completas de Rui Barbosa: edição e sociabilidades intelectuais (1930-1949). 2012. Tese (Concurso para professor titular em Ciências aplicadas à Educação) Universidade Federal de Minas Gerais, Belo Horizonte, 2012.

FERREIRA, Jorge. O socialismo soviético. In: REIS FILHO, Daniel, Aarão; FERREIRA, Jorge; ZENHA, Celeste (Org.). O século XX: o tempo das crises. Revoluções, fascismos e guerras. Rio de Janeiro: Civilização Brasileira, 2005, p. 79-108.

FIGUEIREDO, Rubens. Gorki - uma obra útil ao regime. Cadernos entre livros, Literatura russa, São Paulo, n. 2, S/A.

FILONOV, G. N. Anton Makarenko. Carlos Bauer, Recife: Fundação Joaquim Nabuco, Editora Massangana, 2010.

FREITAS, Luiz Carlos. Prefácio. In: FREITAS, Luiz Carlos, CALDART, Roseli Salete (Org.). N. K. Krupskaya: a construção da pedagogia socialista - textos selecionados. São Paulo: Expressão Popular, 2017.

GOMES, Ângela de Castro (Org.). Escrita de si - escrita da história. Rio de Janeiro: Editora FGV, 2004.

GÓRKI, Máximo. Três russos e como me tornei escritor. São Paulo: Martins Editora, 2006.

LE GOFF, Jacques. História e memória. Campinas: Editora da Unicamp, 1990.

LILLA, Mark. A mente imprudente - os intelectuais na atividade política. Rio de Janeiro: Record, 2017.

LOPEZ, Luiz Roberto. Produção cultural e revolução soviética. In: VIZENTINI, Paulo F.; RIBEIRO, Luiz Dario T.; LOPEZ, Luiz Roberto; COHEN, Vera R. de Aquino (Org.). A revolução soviética 1905-45: o socialismo num só país. Porto Alegre: Mercado Aberto, 1989.

MAKARENKO, Anton. Poema pedagógico. São Paulo: Ed. 34, 2005. 
MANACORDA, Mario Alighiero. História da educação - da antiguidade aos nossos dias. 13. ed. São Paulo: Cortez, 2010.

MARABINI, Jean. A Rússia durante a Revolução de Outubro. SP: Cia. das Letras: Círculo do Livro, 1989.

MOVIMENTO, Revista de crítica e informação, 1928, p. 20.

REIS FILHO, Daniel Aarão. As revoluções russas. In: REIS FILHO, Daniel, Aarão; FERREIRA, Jorge; ZENHA, Celeste (Org.). O século XX: o tempo das crises. Revoluções, fascismos e guerras. Rio de Janeiro: Civilização Brasileira, 2005, p. 35-59.

SCHERRER, Jutta. Bogdanov e Lenin: o bolchevismo na encruzilhada. In: HOBSBAWN, Eric (Org.). História do marxismo. v. 3. Rio de Janeiro: Paz e Terra, 1987.

SIRINELLI, Jean-François. Os intelectuais. In: RÉMOND, René (Org.). Por uma história política. 2. ed. Rio de Janeiro: Editora FGV, 2003.

STRADA, Vittorio. Da revolução cultural ao realismo socialista. In: HOBSBAWN, Eric (Org.). História do marxismo. v. 9. Rio de Janeiro: Paz e Terra, 1987.

VIZENTINI, Paulo F.; RIBEIRO, Luiz Dario T.; LOPEZ, Luiz Roberto; COHEN, Vera R. de Aquino (Org.). A revolução soviética 1905-45: o socialismo num só país. Porto Alegre: Mercado Aberto, 1989.

WINOCK, Michel. O século dos intelectuais. Rio de Janeiro: Bertrand Brasil, 2000. 
MARCELO HORNOS STEFFENS é historiador, mestre em História pela Pontifícia Universidade Católica (PUC/RS) e doutor em História pela Universidade Federal de Minas Gerais (UFMG). Professor associado do Instituto de Ciências Humanas e Letras (ICHL) da Universidade Federal de Alfenas (Unifal/MG). Atua como pesquisador nos grupos de pesquisa: História do Brasil: memória, cultura e patrimônio (Unifal/MG); América ibérica e suas conexões (Unifal/MG).

E-mail: mhsteffens@uol.com.br

(D) http://orcid.org/0000-0003-0816-7000

Recebido em: 16 de outubro de 2018

Aprovado em: 10 de maio de 2019 